\title{
Especialización Derecho Administrativo
}

\section{DESCENTRALIZACIÓN: ¿UNA HERRAMIENTA DE PRIVATIZACIÓN?}

\section{Decentralisation: an instrument of privatisation?}

\author{
Oscar Fernando Amado Garrido*
}

Fecha de entrega: 8 de febrero de 2007

Fecha de aprobación: 11 de mayo de 2007

Fecha de evaluación: 13 de junio de 2007

\section{Resumen}

A pesar de las críticas sobre el tamaño del Estado, la descentralización sirvió para la creación de un gran número de entidades públicas, las cuales, sin embargo y con el paso del tiempo, perdieron su rumbo y se quedaron como fortín político y centros burocráticos. Sin embargo, desde la reforma introducida por la Ley 489 de 1998, la descentralización se acentuó mediante la creación de personas jurídicas indirectas, o sea, asociaciones de entidades públicas, que se rigen por las normas del derecho privado. Su finalidad fundamental fue seguir la operación de aquellas empresas estatales que fueron disueltas, pero ahora siguiendo las normas del derecho privado y la consecuente participación de particulares, por lo cual se afirma que este tipo de organismos se constituye en una forma de privatizar el Estado.

Docente de pregrado y postgrado de la Facultad de Derecho de la Universidad Santo Tomás 


\title{
Palabras clave
}

Decentralización administrativa, privatización del Estado.

\begin{abstract}
Despite critics about government size, the decentralization was a important tool for a huge number of public societies, corporations and more, which lost their objectives and were reduced as a rat hole public funds. However, since Law 489 of 1998, this phenomenon (decentralization) ground up as a indirect public enterprises, means merger or public corporations association. Their most important goal was to continue the operation of dissolved public corporation, but ruling by private (civil and commerce) law now, and allowing private person to be a part of the "business", by which critics says the state is "outsourcing".
\end{abstract}

\section{Key words}

Administrative decentralisation, privatisation of the state.

\section{ANTECEDENTES HISTÓRICOS}

En la reforma constitucional de 1968 , se establece por primera vez la normatividad para dotar al Estado de herramientas que permitan hacer más efectiva su intervención. A través de los Decretos 1050 y 3130, principalmente, se establecen las personas jurídicas estatales a través de las cuales el Estado actuará de modo descentralizado $^{1}$, aunque se dejó también abierta la posibilidad de que particulares asumieran las funciones estatales ${ }^{2}$.

Estas normas fueron expedidas dentro de la concepción cepalina de intervención estatal a través de entidades públicas, es decir, enteramente estatales, donde los particulares intervendrían únicamente si el propio Estado los invitaba y se asociaban con él, con lo cual los excluía de sectores trascendentales de la economía. Así el Estado demostraba quién mandaba en la economía, y se reservaba para sí las actividades consideradas como estratégicas. Sin embargo, algunos consideran que estas normas lo único que hicieron fue definir el carácter de públicas de algunas entidades estatales que ya estaban creadas con anterioridad, dejando establecido con claridad el régimen legal que les era aplicables $^{3}$.

1 Tenemos que estas normas delimitaron el marco jurídico de los Establecimientos Públicos, las Empresas Industriales y Comerciales del Estado, las Sociedades de Economía Mixta, así como las sociedades de derecho público (constituidas entre entidades públicas).

2 Recordemos que estas normas preveían la llamada "descentralización por colaboración", fundamentalmente para permitir la legalidad de las actuaciones de las Cámaras de Comercio y la administración por parte de la Federación Nacional de Cafeteros del Fondo Nacional de Café, a través de un convenio con el Ministerio de Hacienda.

3 A modo de ejemplo, para 1968 ya existían Ecopetrol (creada en 1948) y Telecom (creada en 1949), las cuales se consideraban como "establecimientos públicos", lo cual creó problemas acerca del régimen de sus actuaciones, esto es, si eran comerciales o públicas, y cuáles se consideraban de derecho privado o de Derecho Administrativo. 
Lo anterior dio lugar a la creación de un considerable número de entidades estatales descentralizadas, sin criterios económicos de sostenibilidad. Por el contrario, muchas de ellas fueron calificadas como "elefantes blancos", fortines políticos donde se saciaban las apetencias clientelistas de los congresistas, diputados, concejales, y en fin, de quienes detentaban el poder político. De ahí la necesidad de su disminución en número y funciones ${ }^{4}$.

\section{LA NUEVA CONSTITUCIÓN POLÍTICA Y SU DESARROLLO JURÍDICO}

Durante el gobierno de César Gaviria, economista de profesión, y quien fuera ministro de Virgilio Barco, se dio un importante impulso a la intervención privada en los asuntos estatales, dejando al Estado únicamente con funciones regulatorias y de control y vigilancia en aquellos casos donde se consideraba que el sector privado ejercería su actividad con mayor eficiencia, pero se debía velar por el interés general y la preservación del bien público ${ }^{5}$. Para lograr este objetivo, se necesitaba cambiar la concepción paternalista del Estado, lo cual suponía una reforma de la Constitución en este sentido. Afortunadamente para los intereses del gobierno, se dio el caso de la Asamblea Nacional Constituyente, en la cual se aprovechó para reformar también el tema económico, acorde a las expectativas del presidente y su equipo económico. Es de recordar, que en esta época (principios de la década de 1990), se vivía en Latinoamérica una corriente reformista del Estado, guiada por una corriente de pensamiento partidaria de recortar el tamaño y funciones estatales para ser asumidas por particulares. Ello siguiendo en parte el modelo chileno implantado por Pinochet, de acuerdo a las teorías de la denominada "Escuela de Chicago" ${ }^{\text {, }}$ que se plasmó en muchas Constituciones políticas del subcontinente ${ }^{7}$.

En Colombia, la Constitución Política de 1991, dedica un capítulo a la actividad económica y la Intervención estatal. Concretamente, en los artículos 333 a 340, establece las directrices de la intervención estatal en la economía, con funciones regulatorias principalmente, pero manteniendo la posibilidad de intervención estatal directa ${ }^{8}$. Lo anterior, conlleva a una nueva repartición de competencias en las entidades estatales, para lo cual la propia Constitución faculta al Estado para hacer el ajuste respectivo, pudiendo en consecuencia suprimir, fusionar o reestructurar las entidades estatales para acomodarlas a los nuevos mandatos constitucionales ${ }^{9}$.

Los decretos correspondientes ${ }^{10}$ dieron un enfoque más económico a las entidades estatales. A modo de ejemplo en esta reestructuración estatal, se dio lo siguiente:

- Telecom, que fue durante casi 40 años establecimiento público, se convierte en empresa industrial y comercial del Estado, con el fin de poder competir en el campo de las telecomunicaciones.

$4 \quad$ En los planes de desarrollo de los gobiernos de Virgilio Barco (1986-1990) y César Gaviria (1990-1994), se encuentran ejemplos de estas situaciones. Recordemos que durante la administración Barco se liquidó el Insfopal, que aunque se consideraba el inicio de una supresión de entidades inútiles, solamente quedó con este proceso.

5 Plan Nacional de Desarrollo "El cambio es ahora 1990-1994", Departamento Nacional de Planeación, Bogotá, 1990.

6 Esta corriente económica, llamada así por salir de economistas de la Universidad de Chicago, asegura que las leyes del mercado son el mecanismo más idóneo para corregir las desigualdades sociales. El Estado tendrá un papel de regulación de la actividad económica, buscando el bienestar general , pero su intervención directa serà la mínima posible: serà la libertad económica e iniciativa del particular la que actùe en el ciclo económico. Por esto a esta escuela se le considera una nueva versión del liberalismo económico, llamada "neoliberalismo".

7 Recordemos Alberto Fujimori en Perú, Carlos Menem en Argentina, Fernando Color de Mello en Brasil, por citar los más importantes, como exponentes de esta nueva corriente económica que se vio plasmada en las constituciones de estos países.

8 Artículo 340 de la Constitución de 1991.

9 Artículo Transitorio 20 ídem.

10 Los Diarios Oficiales 40701, 40702 y 40703, todos de 1992 compilan los decretos expedidos. 
- Adpostal, también establecimiento público, se convierte igualmente en empresa industrial y comercial del Estado, para tener mejor capacidad de competencia en el sector de la mensajería.

- $\quad$ Al ICA, se lo mantiene como establecimiento público, pero cambia su naturaleza, sus funciones, y sobre todo, la investigación con fines de desarrollo del sector agropecuario, que deberá ser mediante el sistema de coparticipación, es decir, los ganaderos y agricultores determinarán los objetivos y los proyectos investigativos a desarrollar. Corpoica (denominación adoptada con la reforma) deberá desarrollar su labor de acuerdo a los intereses del sector privado.

- El Servicio Naviero de la Armada (Senarc), se suprime, debido a que se considera que coarta al sector privado para la construcción y reparación de naves.

- Las superintendencias de valores, de industria y comercio, y la de sociedades son dotadas con facultades sancionatorias más precisas y estrictas, pero mediante control posterior a la infracción.

Esta reforma de 1992, constituye un inicio importante en la nueva concepción de descentralización, ya que las entidades cambian su concepción para convertirse en entidades "de servicio", es decir, con un enfoque de atención al cliente igual al que se maneja en las áreas comerciales de las empresas del sector privado. El Estado ya no es quien impone, sino quien dirige el aparato productivo $y$ ejerce funciones orientadoras $y$ de defensa de los más necesitados. Pero lo primordial es permitir al particular ejercer su derecho a la libertad económica y a su libre iniciativa.
El Estado actuará para corregir las desviaciones que se presenten. La actuación estatal será posterior a la conducta realizada.

Todas estas modificaciones, dejaron ver una cosa: la legislación preexistente a la Constitución de 1991, debía ser modificada para actualizar la administración pública a las nuevas funciones y así adecuar su estructura. Se ve entonces la necesidad de armonizar las leyes a la nueva Carta Política.

\section{LA LEY 489 DE 1998}

En la Administración de Andrés Pastrana (1898-2002), se expide el nuevo Estatuto General de la Administración Pública, mediante la Ley 489 de 1998. Para el gobierno es clara la necesidad de ajustar la Administración Pública a las nuevas realidades constitucionales ${ }^{11}$. Reconoce igualmente que las normas contenidas en los decretos 1050 y 3130 de 1998 deben ser modificadas y actualizadas a la nueva normatividad superior en la siguiente forma:

- Se mantienen las entidades descentralizadas en el Gobierno Nacional: establecimientos públicos, empresas industriales y comerciales del Estado, sociedades de economía mixta. Se añaden las entidades creadas por leyes especiales, como por ejemplo las Empresas Sociales del Estado, establecidas en la Ley 100 de 1993.

- Se mantienen las asociaciones entre personas jurídicas públicas (denominadas en esta ley asociaciones y fundaciones).

- El control de tutela que el gobierno nacional ejerce sobre las entidades descentralizadas se mantiene.

11 Ministerio del Interior. El cambio en la administración pública: Ley 489 de 1998". Serie Documentos número 4, Santa Fe de Bogotá, enero de 1999 
Pero esta Ley, trae aspectos novedosos que serán la base para acentuar la descentralización por servicios:

- Establece que las asociaciones entre personas jurídicas estatales se regirán por las normas del derecho privado. En la normatividad derogada se establecía que el derecho administrativo sería la base de este tipo de asociaciones.

- El presidente de la República queda facultado para suprimir entidades estatales si no cumplen la misión para la que fueron creadas, o si financieramente no son sostenibles. Esta ley reglamenta los numerales 15 y 16 del articulo 189 de la actual Constitución Política, pilar de esta facultad legal.

- $\quad$ Se permite la delegación de funciones públicas, incluyendo la delegación a particulares.

Igual que en la reforma constitucional de 1991, se faculta al gobierno para adecuar la administración pública a los postulados de esta ley ${ }^{12}$. Las actuaciones realizadas por el gobierno con fundamento en esta ley, aún tienen una alta repercusión tanto económica como jurídica. Como ejemplos tenemos:

- La supresión de la Caja Agraria, y en su lugar se constituyó el Banco Agrario de Colombia que entró a asumir sus funciones. Es de anotar que el Banco Agrario es una sociedad entre entidades públicas, de acuerdo a la Ley
$489^{13}$, y recientemente se ha puesto como ejemplo de recuperación de una entidad financiera en crisis $^{14}$.

- El Fondo Nacional de Ahorro, empresa industrial y comercial del Estado, funcionará según las normas de la entonces Superintendencia Financiera, es decir, funcionará como un banco particular. Sin embargo, esta reestructuración no duró mucho ${ }^{15}$, pero en las nuevas políticas establecidas por la Junta Directiva del Fondo, el nuevo enfoque ha sido similar al de la banca privada.

La figura de las sociedades entre entidades públicas, ha sido en consecuencia la preferida por el gobierno a la hora de suprimir o modificar la estructura de la administración pública. Entidades consideradas imprescindibles en la estructura estatal, han sufrido los efectos de la política de racionalización del aparato estatal:

- Ecopetrol fue escindida en dos entidades: Ecopetrol S.A., sociedad por acciones de carácter estatal, y la Agencia Nacional de Hidrocarburos, que dentro de la estructura estatal se considera una Unidad Administrativa Especial. La agencia se encargará de definir la política petrolera establecida por el Gobierno Nacional, mientras que Ecopetrol S.A. ejecutará en representación del Estado la explotación y exploración de campos petroleros, por sí misma o mediante el sistema de asociación con los particulares. En la norma que permitió la creación de Ecopetrol S.A. ${ }^{16}$, se estable-

12 Artículo 120 de la Ley 489 de 1998. Sin embargo esta norma posteriormente fue declarada inexequible por la Corte Constitucional, por vicios de trámite (Sentencia C470/99).

13 Ver Decreto 1065 de 1999 mediante el cual se crea el Banco Agrario de Colombia.

14 En las reuniones de la Asociación de Entidades Bancaria e Instituciones Financieras de Colombia (Asobancaria) se ha reconocido al Banco Agrario como ejemplo de solución de crisis. En el periódico Portafolio no son pocos los artículos que hablan de los logros del Banco, y en las publicaciones de la Superintendencia Financiera sobre utilidades de las entidades vigiladas, se lee desde hace casi 4 o 5 años las utilidades que arroja el Banco Agrario de Colombia.

15 El Decreto expedido para reestructurar el Fondo Nacional de Ahorro se hizo con base las facultades del articulo 120 de la Ley 48 de 1998. Como dijimos en la nota 12, este artículo fue declarado inexequible por vicios de tràmite, en consecuencia se considera que también el decreto ha perdido fuerza ejecutoria por haber desaparecido su fundamento legal (artículo 66 numeral $2^{\circ}$ del CCA). 
ce expresamente que las acciones de la empresa no podrán ser vendidas al sector privado. Por ello, fue necesario la aceptación de una ley que permita la venta de acciones de Ecopetrol S.A. a los particulares, como primer paso para la anunciada venta del $20 \%$ de las acciones al sector privado para financiar la empresa con el fin de atender las actividades de exploración de manera más adecuada.

- Telecom, que en la reforma constitucional de 1991 había pasado a ser empresa industrial y comercial del Estado, fue suprimida y en su lugar se creó, también mediante la figura de la sociedad entre entidades públicas, Colombia Telecomunicaiones S.A. E.S.P., para operar los servicios y activos de la liquidada Telecom., que quedará como una marca de la nueva sociedad. De esta manera, se puede asociar con otras empresas para explotar los servicios de telecomunicaciones, como el reciente caso de la alianza estratégica con la española Telefónica.

- Adpostal, empresa industrial y comercial del Estado a partir de 1991, tambièn fue suprimida y en su lugar se creó la empresa Servicios Pales Nacionales, también sociedad entre entidades públicas, que manejará la marca Adpostal y los activos de la liquidada empresa.

- Inravisión, fue suprimida y en su lugar se estableció Radio y Televisión deColombia, RTVC, también como sociedad entre entidades públicas, la cual se encargará de explotar los Canales de Televisión Públicos y las frecuen- cias de la Radio Nacional, que serán manejados con criterio de sostenibilidad económica ${ }^{17}$.

Pero también la asociación entre entidades públicas ha servido para negocios productivos. El caso más representativo es OLA, cuya empresa Colombia Móvil S.A., es el resultado de la asociación entre la Empresa de Telecomunicaciones de Bogotá ETB y las Empresas Públicas de Medellín EPM, para operar los servicios de comunicación personal PCS que ganaron en licitación hace 3 años.

Con la anterior reseña, vemos que el ejercicio de la descentralización por servicios implica la existencia de eventos en los cuales la persona jurídica de derecho público, comparte su función con un particular, o simplemente, desaparece para que el particular asuma dicha función. Por ello los sindicatos de trabajadores estatales consideran que estos tipos de descentralización implican reducción del Estado, o como dicen ellos mismos "la privatización de lo público"18.

\section{LA DELEGACIÓN DE FUNCIONES A PARTICULARES}

Esta innovación de la Ley 489 de 1998, permite que los particulares asuman funciones estatales. Para ello existen unos requisitos ${ }^{19}$ que se deben seguir para ello. Podemos resumirlos así:

- La delegación al particular siempre será por escrito.

- Debe mediar un acto previo a la delegación.

17 En el Decreto que crea RTVC, se lee que serán funciones de la nueva empresa, entre otras, la consecución de auspicios, patrocinios para la operación de las frecuencias AM FM y franja juvenil de la Radio Nacional. Estas figuras son propias del sector de las comunicaciones comerciales, no se habían dado en la radiodifusión publica.

18 Manifiesto de la Federación Nacional de Trabajadores al Servicio del Estado FENALTRASE, el día 01 de mayo de 2006 en la ciudad de Bogotá, durante las marchas del Día del Trabajo.

19 Artículos 10, 11, 12, 111, 112, 113 de la Ley 489 de 1998. 
- En ningún caso, la entidad pública que delega pierde control sobre las funciones delegadas. Tan es así, que en cualquier momento la entidad puede cancelar la delegación o autorización.

- No puede el particular sustituir los procedimientos señalados por ley para ciertos casos, debe seguirlo igual como si la atención la brindara directamente la entidad pública.

- Deben pactarse las calidades mínimas de las personas que ejercerán la función delegada.

- Si es el caso, pactarse una remuneración al particular.

- $\quad$ No puede delegarse en particulares la facultad de expedir regulaciones de carácter general, ni de aquellos asuntos que no sea posible delegar.

- $\quad$ Si se delegan funciones administrativas, debe existir un convenio.

- $\quad$ Se debe seguir un proceso de convocatoria pública para escoger la persona particular que ejercerá dicha función.

- $\quad$ El régimen de los actos del delegado es el mismo que tendrían si los expidiera directamente la entidad delegante.

- No pueden delegarse funciones por más de cinco (5) años ${ }^{20}$.
Un ejemplo de delegación podemos encontrarlo en el manejo del Registro Automotor de Bogotá. Esta función la cumple la Secretaría de Tránsito y Transporte de la capital de la República, a través de la empresa Servicios Especializados en Tránsito y Transporte SETT. Para esta función, se suscribió un contrato de concesión donde SETT se compromete a llevar y actualizar toda la información relativa a los vehículos automotores matriculados en la ciudad de Bogotá, y a cambio recibe una remuneración civil por parte de dicha Secretaría. Los empleados del SET, frente a la comunidad, parecen empleados estatales ya que se manejan los mismos procedimientos, formularios y términos existentes en las oficinas de Tránsito estatales, pero realmente son contratistas particulares (la mayoría por prestación de servicios) del SETT.

El SETT no tiene ningún control de las Inspecciones de Tránsito como muchos erróneamente lo creen. Esta función la ejerce directamente la Secretaría de Tránsito y Transporte por intermedio de sus empleados públicos. Tampoco le compete al SETT la asignación de las matrículas (placas) de los vehículos, esta función corresponde directamente a la Secretaría de acuerdo al rango de numeración que asigna el Ministerio del Transporte. EI SETT se encarga de registrar los movimientos de las placas, no su creación.

En un reciente estudio de la Universidad Nacional como interventora del contrato entre el SETT y la Secretaría de Tránsito y Transporte ${ }^{21}$, se encontraron problemas referidos a la inscripción irre-

20 La norma inicial de la Ley 489 de 1998 establecía que la delegación se puede hacer por cinco (5) años prorrogables, sin embargo la Corte Constitucional, en sentencia C - 570 de 2003 estableció que era inexequible la palabra "prorrogables". En los considerando del fallo, se deja en claro que la función administrativa delegada a los particulares es transitoria y no permanente.

21 Interventoría al Contrato de Concesión SETT-Tránsito de Bogotá. Abril de 2006, publicado en el periódico HOY de los días 25, 26, 27 y 28 de octubre de 2006 . 
gular de traspasos de vehículos, placas duplicadas de modo fraudulento, duración excesiva e injustificada de los trámites ante el SETT, etc. Sin embargo, las críticas que hemos visto sobre este informe han sido dirigidas a la Secretaría de Tránsito $^{22}$, reflejando de manera muy exacta la situación de confusión entre el delegante (en este caso la Secretaría de Tránsito) y la entidad delegada (el SETT). Surge, entonces, el interrogante acerca de la conveniencia de mantener en manos particulares una labor pública como lo es el Registro Público Automotor de Bogotá. Si bien es cierto el Código Nacional de Tránsito ${ }^{23}$ establece que es un registro público, no prohíbe su administración por parte de particulares. Sin embargo, es necesario ver no sólo la legalidad del convenio, sino también la gestión eficiente por parte de los particulares.

El caso del Registro Automotor de Bogotá es un caso concreto de descentralización mediante delegación a particulares de funciones administrativas. Pero no ha sido el único: curiosamente en la misma Secretaría de Tránsito, se propuso en 1998 entregar a particulares el cobro de las multas por infracciones a las leyes de tránsito ${ }^{24}$. Sin embargo, no pasó de un anuncio, ya que la propia Secretaría encontró "inconvenientes jurídicos" (que nunca dijo cuáles eran) para entregar el cobro de cartera estatal a los particulares. Según un informe del diario El Espectador ${ }^{25}$, la entrega no se hizo porque la cartera vencida por multas e infracciones se encontraba prescrita, ya que el entonces Código de Tránsito establecía una prescripción de seis (6) meses, y la cartera a cobrar estaba en su gran mayoría por fuera de este lapso.
También a nivel nacional el cobro de impuestos ha estado en los proyectos del gobierno para su traslado a particulares. En el año 2003, la Dirección de Impuestos y Aduanas Nacionales DIAN, informó que entregaría a particulares la cartera en mora por concepto de impuestos, tasas y demás contribuciones administradas por ella ${ }^{26}$. Según la justificación estatal, se requería un esfuerzo adicional para aumentar el recaudo y fortalecer el cobro de las obligaciones tributarias en procesos especiales (reestructuración Ley 550 entre otros). Hasta en la página de Internet de la DIAN se publicó el prepliego de la licitación para escoger la firma respectiva, que debía reunir requisitos de experiencia en el cobro de cartera financiera, y un call center para llamar a los deudores tributarios.

El proyecto no avanzó, ya que jurídicamente se discutía la validez de entregar dicha función de cobro a los particulares, sin mencionar la discusión acerca de la gestión de la DIAN que justificara esta actuación. En el trámite de la reforma tributaria de $2003^{27}$, se establecía la figura del gestor de cobro, consistente en un particular que haría la labor de cobro persuasivo (antes del Mandamiento de Pago), quien sería remunerado de acuerdo a lo recaudado y a una tarifa que se deniminaba en el proyecto como costa o ges tión de cobranzas. Con esta figura se podría entregar la cartera de la DIAN a los particulares. Sin embargo, la ley resultante eliminó la figura del gestor y no permitió que en consecuencia que la anunciada licitación se llevara a cabo. Se discutía si el particular actuaba delegado por el Estado, o simplemente como un mandatario. La

22 Varios concejales de Bogotá han llegado a sugerir la eliminación de la Secretaría de Tránsito y Transporte por la corrupción reflejada en parte por el informe de la Universidad Nacional. Periódico HOY de 26 y 27 de octubre de 2006. La Administración Distrital acogió las criticas y en la última reforma del distrito suprimió dicha secretaria, colocando una nueva rectoría y secretaría de modalidad.

$23 \quad$ Ley 768 de 2002

$24 \quad$ Noticiero CM\&. Emisión de octubre 20 de 1998.

25 El Espectador, edición de 25 de enero de 1999.

26 La República, Edición de noviembre 13 de 2003.

27 Que vendría a ser la Ley 863 de 2003. 
tesis estatal era que el particular que cobra, actúa como particular en ejercicio de funciones administrativas, pero varios particulares que estaban interesados comentaron que su labor era igual a la de un abogado en un proceso ejecutivo ${ }^{28}$. Sin embargo, como la ley aprobada eliminó la posibilidad de un gestor externo a la DIAN para el cobro, la discusión no trascendió.

Sin embargo, después de este tema de externalización de cartera estatal, se ha llegado al consenso en el gobierno de que jurídicamente no hay figura que impida hacerlo, pero la responsabilidad del Estado frente a las actuaciones del particular encargado y frente al deudor acababa en todo caso llegando a la entidad estatal acreedora, ya que es claro que el particular no es un simple mandatario, sino que tiene investidas funciones administrativas. Por ello, era necesario establecer por ley la prohibición de entregar el cobro de cartera a los particulares. En el proyecto de ley de Normalización de Cartera ${ }^{29}$, se estableció expresamente que ninguna entidad estatal podría entregar el cobro de la cartera tributaria a particulares. Sin embargo, durante el trámite del proyecto, la prohibición se suavizó, y en la norma original se limitó la prohibición únicamente a las entidades territoriale ${ }^{30}$. Finalmente, en el texto conciliado en el Congreso, se eliminó la prohibición, y no quedó ninguna norma que impida a los entes estatales entregar el cobro de su cartera.

\section{CONCLUSIÓN}

Si bien es cierto la descentralización por servicios es necesaria para el cumplimiento de las finalidades estatales consagradas en la Constitución Políti- ca y en las leyes, no ha estado exenta de tratamiento político que desdibuja la bondad de la intención inicial, por lo cual, se ha visto muy limitado este instrumento para su plena aplicación.

La Ley 489 de 1998, establece que no se pueden delegar en particulares aquellas funciones que no sean propias de delegación ${ }^{31}$. Esto es una estipulación muy ambigua, que no permite señalar claramente, qué operaciones o actividades administrativas sean posibles de delegar. Y aquí la discusión sigue, ya que fuera de las actividades de defensa y seguridad, legislación y administración de justicia, cualquier otra actividad que haga el Estado no está claramente definida como de resorte exclusivo estatal, por lo cual es imposible hacer una descentralización sin considerar, descontados los casos señalados, que los particulares no puedan prestarlo con mayor eficiencia para el cumplimiento de los fines estatales. La discusión está abierta, y en todo caso se debe tener presente que sin importar si es el Estado o los particulares los que presten un determinado servicio o función, es al administrado quien, en últimas, está sometido a las consecuencias de una determinación de este tipo.

\section{BIBLIOGRAFÍA}

Departamento Administrativo de la Presidencia de la República. (1998, 1999, 2000). Memorias al Congreso de la República. Bogotá: Imprenta Nacional.

Departamento Nacional de Planeación. (19741978). El mandato claro. Plan Nacional de Desarrollo del Gobierno de Alfonso López Michelsen. Bogotá.

\footnotetext{
$28 \quad$ La República, Edición de enero 18 de 2004.

29 Que llegaría a ser la Ley 1066 de 2006.

30 Gaceta del Congreso de fecha 03 de agosto de 2005.

$31 \quad$ Ley 489 de 1998 articulo 11.
} 
Departamento Nacional de Planeación. (19901994). El cambio es ahora. Plan Nacional de Desarrollo del Gobierno de César Gaviria Trujillo. Bogotá.

Departamento Nacional de Planeación. (19861990). Cambio para construir la paz. Plan Nacional de Desarrollo de Virgilio Barco Vargas. Bogotá.

Departamento Nacional de Planeación. (20022006). Hacia un estado comunitario. Plan Nacional de Desarrollo de Alvaro Uribe Vélez. Bogotá.

Henao, J. (1991). Derecho administrativo general y colombiano. Bogotá: Editorial Temis.
Ministerio de Justicia y del Derecho. (1996, 1997, 1998). Memorias al Congreso de la República. Bogotá: Imprenta Nacional.

Ministerio del interior. (2000, 2001). Memorias al Congreso de la República. Bogotá: Imprenta Nacional.

Rodríguez, L. (1980). Derecho administrativo general. Bogotá: Editorial Temis.

Younes, D. (1984). Derecho administrativo laboral. Bogotá: Editorial Temis. 